\title{
Surface Defect in Telescopic Front Fork: A Metallurgical Analysis
}

Souvik Das ${ }^{1 *}$, Janak Lal ${ }^{2}$, Arthita Dey ${ }^{1}$, Goutam Mukhopadhyay ${ }^{1}$ and Sandip Bhattacharya ${ }^{1}$

${ }^{1} R \& D$ and Scientific Services, Tata Steel Limited, Jamshedpur, India

${ }^{2}$ Product Technology Group, Tata Steel Limited, Jamshedpur, India

\begin{abstract}
Adaptive Front Fork (TFF) utilized as a part of bikes, predominantly cruiser, is produced using high quality steel, and is made by high recurrence acceptance welding process where in hot rolled and cured loops are utilized as information crude material for moving of empty tubes took after by warm treatment, surface treatment, chilly drawing, tempering and so on. The last application requests unrivalled quality TFF tubes w.r.t. surface complete and dimensional resilience. This paper displays the examination of two distinct sorts of disappointment of fork amid activity. The examination comprises of visual review, substance investigation, portrayal of microstructure, and vitality dispersive spectroscopy. In this paper, two fizzled tube tests have been researched. In one case, the outcome uncovered that there was a previous split, known as snare break, which prompt the splitting of the tube. Metallographic examination showed that amid field activity the prior snare break was surfaced out prompting split in the pipe. For another situation, nearness of throwing powder with decarburised grains inside the material demonstrates starting point of the deformity from its crude material at piece organize.
\end{abstract}

Keywords: Telescopic front fork; Induction welding; Internal oxidation; Hook crack

\section{Introduction}

The most common form of front suspension for a modern motorcycle is the telescopic front fork (TFF), (Figure 1). The front fork is essentially a large hydraulic shock absorber with internal coil springs. The fork gets together associates bike's front haggle to its edge, regularly by means of a couple of triple clips. The front fork prevents excessive weight on the front wheel during sudden application of the brake and softens bumping when driving on rough road surfaces. The Fork assembly mainly contains fork tubes and suspension components (coil springs and damper) which allow steering of the bike through handle bar attached to the top clamp. Springs not only hold up the bike and support both the static load of the bike and the rider, but are also sized or rated to accommodate expected bump loads (Figure 1).

The front fork tube is manufactured from structural grade steel and it attributes high strength, surface finish, ease of manipulation, and closer dimensional tolerance. Initially the coil is loaded on the lock side of double mandrel un-coiler (DMU) by a cantilever crane and the strap is being cut out manually, followed by straightening of the end of the coil material by pinch roll flattener, only the ends are levelled for coil end welding. Then the ends of the coils are welded by MIG welding procedure. The strips are accumulated vertically on a larger radius in continuous coil accumulator (CCA). The coil is pickled and pickled slit coils are fed at tube mills for manufacturing of the tube. The continuous strip coming out of stamping unit is formed to a tubular shape in tube mill. The forming of the strip is initiated by a special w-pass roll drive followed by four pairs of horizontal- vertical rollers. Ultimately fin-pass is used to precise the weld bead thickness. Continuous high frequency induction (HFI) welding takes place and the tubular-shaped strip is properly formed into a tube. The HFI welding method utilizes pressure and heat in order to join the strip edges of the open seam tube together without the addition of a filler metal. Converging strip edges are pushed against each other by shaped squeezed and pressure rolls in the welding stand. The welding current is introduced into the open seam tube by inductive means using multi-wind coils. The tube welding machine works always at a speed of $80-90 \mathrm{~m} / \mathrm{min}$. The pipe goes through roller hearth heater for normalizing at $880-900^{\circ} \mathrm{C}$. At that point surface treatment is done on the tubes took after by chilly illustration. Tubes are again put inside the roller hearth heater to temper them at around 600 $\pm 20^{\circ} \mathrm{C}$. The tubes are gone through a couple of cooling troughs. These tubes are made alongside some resilience to place them in the required creation estimate. Non-damaging testing (NDT) is done to check any kind of defects in the welding break and parent material and also in surface imperfections. The defect products are rejected immediately. The manufactured tubes in run out table (ROT) unit run through a series of roll conveyors up to the online inspection division and cooled down during the process. The initial segment of the unit acknowledges or rejects a tube according to modified sensors. Next part comprises of a pneumatic gaseous tension chamber, cleans trimmed parts of the tubes. At last, the tubes leaving the assessment chamber are put away aside for quite a while, at that point according to the necessity, the tubes are sent to tempering/normalizing area or water driven testing segment or dispatched as it seems to be. The schematic graph of the point by point process is shown in Figure 2.

The two-wheeler industry has been witnessing double digit growth over the last couple of years. This is reflected in higher production of motorcycles, leading to the demand of TFF tubes growing in recent times. Whereas failure of TFF tubes during production leads to huge damage and decrease the productivity. The present work has been focused on analysis of two different cases related to surface defect of TFF tubes.

\section{Experimental Procedure and Results}

\section{Sample characteristics}

Two fizzled tube tests were gathered from the illustration process for examinations. The examples were cleaned with $(\mathrm{CH} 3)_{2} \mathrm{CO}$ to

*Corresponding author: Souvik Das; R\&D and Scientific Services, Tata Steel Limited Jamshedpur 831 001, India, Tel: +917461041880; E-mail: souvik.das@tatasteel.com

Received July 13, 2018; Accepted August 06, 2018; Published August 13, 2018

Citation: Das S, Lal J, Dey A, Mukhopadhyay G, Bhattacharya S (2018) Surface Defect in Telescopic Front Fork: A Metallurgical Analysis. J Steel Struct Constr 4: 143. doi: $10.4172 / 2472-0437.1000143$

Copyright: (C) 2018 Das S, et al. This is an open-access article distributed under the terms of the Creative Commons Attribution License, which permits unrestricted use, distribution, and reproduction in any medium, provided the original author and source are credited. 

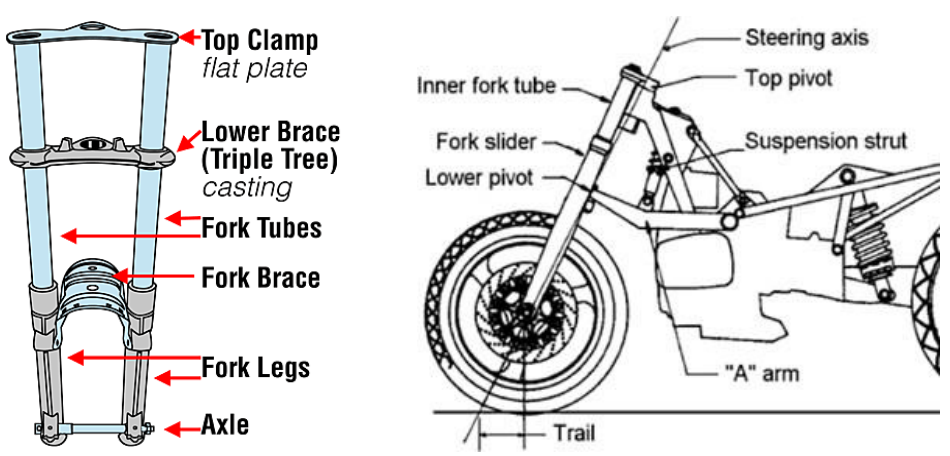

Figure 1: Schematic view of telescopic front fork of motorcycle.

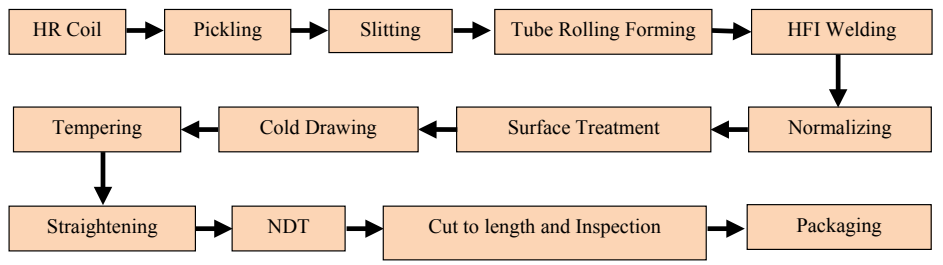

Figure 2: Schematic diagram of TFF production chain.

\begin{tabular}{|c|c|c|c|c|c|c|c|c|}
\hline SI. No. & Type & C & Mn & S & P & Si & $\begin{array}{c}\text { Size } \\
(\mathbf{m m})\end{array}$ \\
\hline Sample\#1 & Tube Sample & 0.40 & 1.42 & 0.010 & 0.033 & 0.170 & 0.052 \\
\hline Sample\#2 & & 0.39 & 1.40 & 0.006 & 0.022 & 0.227 & 0.015 \\
\hline Spec. & SAE 1541 & $0.36 / 0.44$ & $1.35 / 1.65$ & 0.05 max & 0.04 max & $-\cdots$ & $51.10 * 3.55$ \\
\hline
\end{tabular}

Table 1: Chemical composition of failed samples (Wt. \%).

expel earth for visual examination preceding metallographic test arrangement. Transverse and longitudinal examples were produced using the surface deformity area of each fizzled tube tests for leading optical minute examination. These examples were exclusively mounted in conductive mounting and cleaned by traditional metallographic methods for scratch free surface. The cleaned tests were scratched in $3 \% \mathrm{Nital}$ arrangement ( $3 \mathrm{~mL} \mathrm{HNO}_{3}$ in $97 \mathrm{~mL}$ ethyl liquor), and both un-carved and carved examples were analysed in a magnifying lens to watch microstructural constituents. The miniaturized scale hardness of various stages saw in the tube tests was resolved in a pneumatically controlled programmed small scale hardness analyser (LecoLM247AT). A connected load of 100 gf was utilized amid testing, and a few spaces were made to decide the hardness of various stages. Field Emission Gun Scanning Electron Microscope (FEG-SEM) study of the samples was also carried out to identity different phases present in the samples. The analyses were performed at $15 \mathrm{keV}$ accelerating voltage and $5^{10-8} \mathrm{~A}$ probe current.

\section{Chemical analysis}

Compound investigation of tests was done utilizing X-ray fluorescence (XRF) spectroscopy aside from C and S. The carbon (C) and (S) substance were examined by burning infrared procedure. All the materials conformed to SAE1541 structural grade with high 'Mn' and low ' $S$ ' content. Details of the samples are given in Table 1.

\section{Visual observation}

In case of Sample \#1, visual observation of the tube sample showed that longitudinal surface crack along the length of the tube at the circumference close to the weld (Figure $3 \mathrm{a}$ and $3 \mathrm{~b}$ ). The crack was around $4 \mathrm{~cm}$ in length and very thin and difficult to detect easily. As the split was exceptionally shallow inside and out and hard to distinguish so it was recognized by color infiltration test (Figure $3 \mathrm{c}$ and $3 \mathrm{~d}$ ).

In case of Sample \#2, general view of the tube sample with defect is shown in Figure 4a. Multiple chevron marks were observed on the outer surface of the tube. These chevron marks were found to form a single line (Figure $4 \mathrm{~b}$ and $4 \mathrm{c}$ ). Similar marks with less severity and a line mark running through centre of these defects were observed at 180 degree location (Figure 4d).

\section{Microstructure analysis}

If there should arise an occurrence of first example, the un-m inside and out scratched microstructure demonstrated a break, ' $J$ ' type fit as a fiddle and of $0.5 \mathrm{~m}$ (Figure 5a), normal to snare breaking [1]. Facilitate the break was observed to be related with some non-metallic manganese sulfide (MnS) incorporations (Figure 5b) which were further, acclimated through EDS investigation. The full scale double zoom photo of the miniaturized scale test uncovered white bond line related with the break (Figure 5a). The 3\% Nital carved microstructure demonstrated that the split was marginally balanced from the security line of the Cold drawn Electric obstruction Welding (CEW) crease (Figure 5a), however, following the weld stream lines and opened up at the periphery. The snare of the break moved in the direction of upward, as appeared in Figure 5d. The weld flow line of the tubes were good to the chilly drawn structure (Figure $5 \mathrm{~d}$ ) and the lattice uncovered grouped ferrite pearlite structure (Figure $5 c$ and $5 e$ ) normal to such high manganese auxiliary steel grades [2]. 
Citation: Das S, Lal J, Dey A, Mukhopadhyay G, Bhattacharya S (2018) Surface Defect in Telescopic Front Fork: A Metallurgical Analysis. J Steel Struct Constr 4: 143. doi: 10.4172/2472-0437.1000143
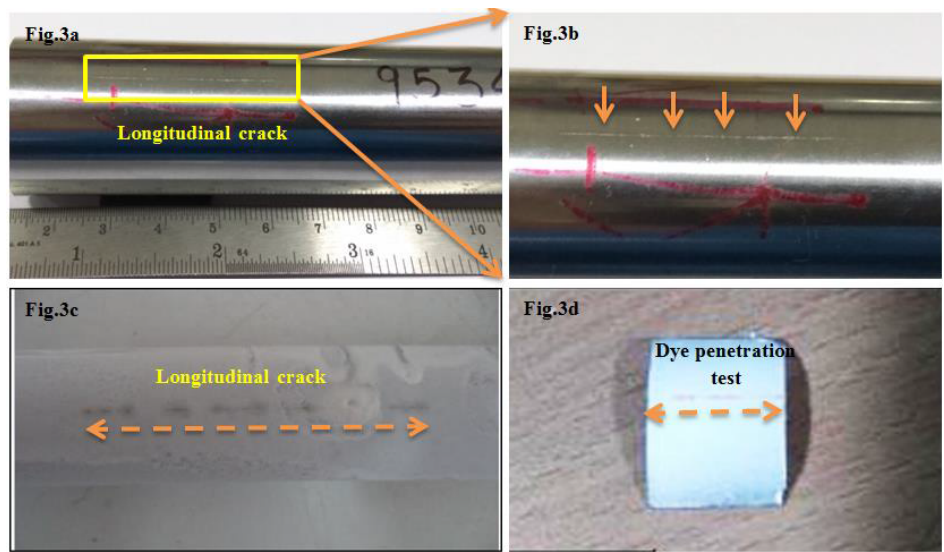

Figure 3: $\mathbf{a}$ and b) Longitudinal surface crack on the tube; $\mathbf{c}$ and d) shows longitudinal crack was detected through dye penetration test

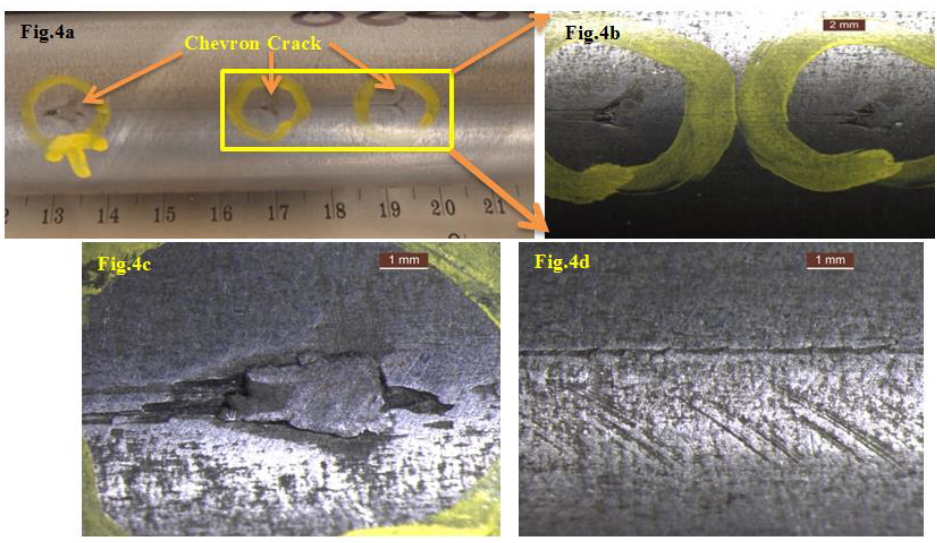

Figure 4: a-c) Chevron cracks on the surface of the tube; d) shows less severity defects were observed at 180 degree location of the chevron crack.
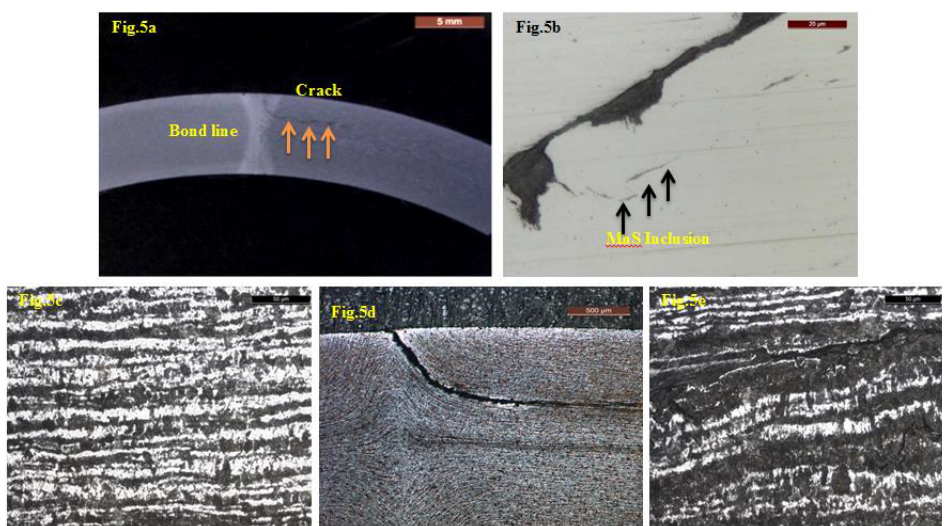

Figure 5: a) Dual image of defect locations; b) un-etched micro image of the defect location; c-e) etched micro image of the defect location at different magnifications.

In case of Sample \#2, un-etched micro image of the samples from defect area revealed bowl shaped defect. This was formed by chippedoff material as shown in Figure $6 a$. Figures $6 \mathrm{~b}$ and $6 \mathrm{c}$ show closer view of the cracks on both edges of the defect. It revealed that the cracks contain some non-metallic entrapments in it. At higher magnification, as shown in Figure 6e, suspected internal oxidation was observed in chipped-off material.
The etched microstructure at the defect location is shown in Figure 7a. Banded ferrite - pearlite structure was observed which followed the contours of the defect/chipped-off material. At higher magnification, decarburised grains were observed along the suspected internal oxidation. The chipped-off material does not show any banding or deformation. However due to accumulation of this material, grains in the matrix below it got deformed which is cold condition effect (Figure 6a-6h). 
Citation: Das S, Lal J, Dey A, Mukhopadhyay G, Bhattacharya S (2018) Surface Defect in Telescopic Front Fork: A Metallurgical Analysis. J Steel Struct Constr 4: 143. doi: 10.4172/2472-0437.1000143

\section{SEM and EDS analysis}

In case of Sample \#1, EDS analysis was carried out on non-metallic inclusion by Field Emission Gun Scanning Electron Microscope. EDS analysis conformed the inclusions as MnS (Figure 7a and Table 2). Inclusion rating was carried out by worst field method as ASTM E 45 to check complete cleanliness of the steel. The inclusion rating, as shown in Table 3, revealed higher level MnS inclusions in steel (Tables 2-3).

Sample \#2: EDS analysis of the dark brown entrapment revealed prominent peaks of $\mathrm{Ca}, \mathrm{Si}, \mathrm{Al}, \mathrm{Na}, \mathrm{F}$ and $\mathrm{O}$ which proves that crack has generated due to mould powder entrapment (Table 4).

\section{Discussion}

If there should be an occurrence of Sample \#1, visual perception of the tube test demonstrated that longitudinal surface split along the length of the tube at the outline near the weld. The break was around $4 \mathrm{~cm}$ long and thin and hard to recognize effectively. The un-etched microstructure revealed a crack, which looks like 'J' type and depth of around $0.5 \mathrm{~mm}$, characteristic to hook cracking .MnS inclusions were observed in the along the crack locations. The overall $\mathrm{MnS}$ inclusion was high as shown in Table 3. Microstructural analysis further revealed that the hook of the crack was turning toward upward surface. The
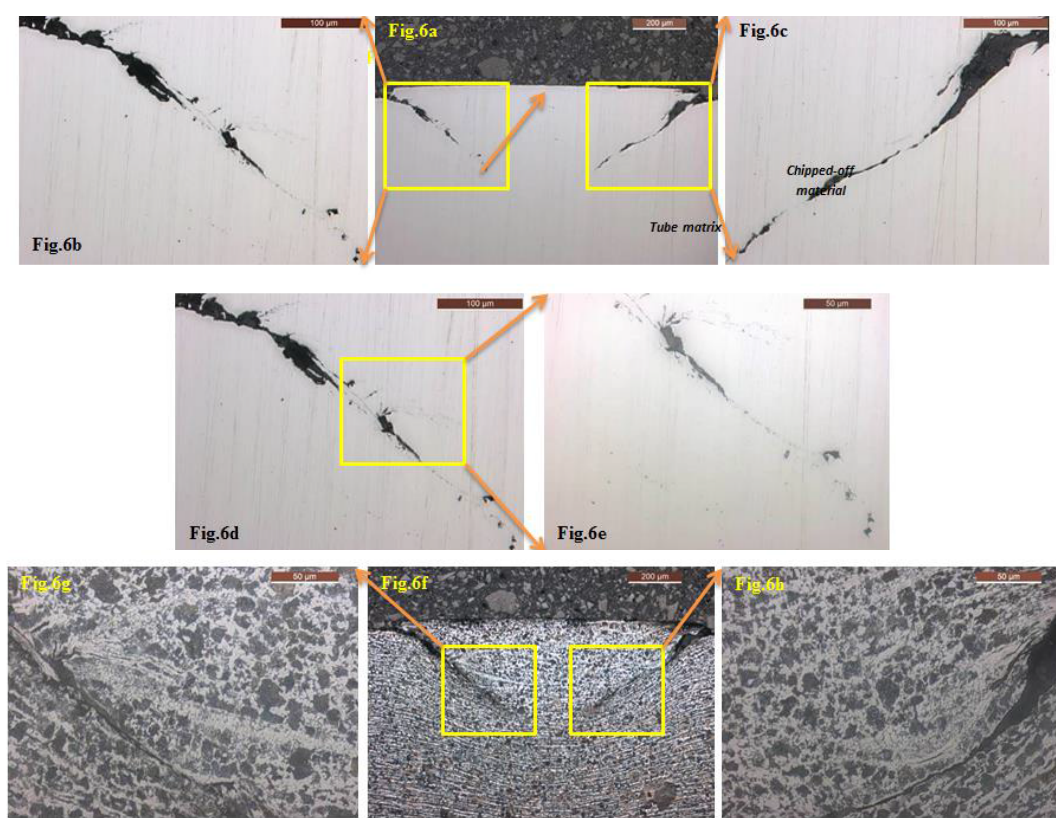

Figure 6: a-d) Un-etched micro image of the defect location at different magnifications; e) presences of dark brown entrapment along with internal oxidation. $\mathbf{f}-\mathrm{h}$ ) etched micro image of the defect location at different magnifications.
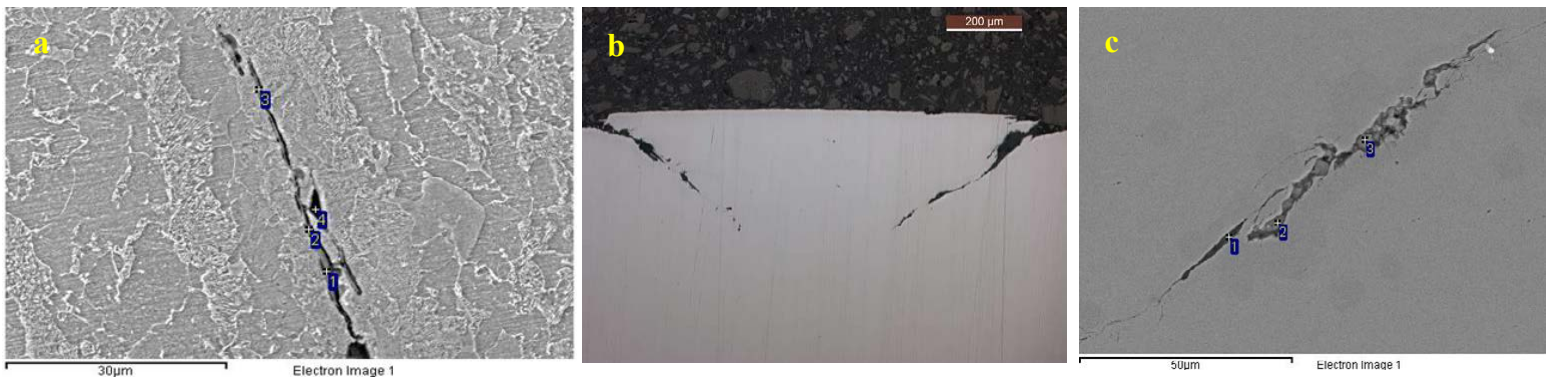

Figure 7: a) EDS analysis of the sample\#1 at cracked location; $\mathbf{b}$ and c) EDS analysis of the sample\#2 at defect location.

\begin{tabular}{|c|c|c|c|c|c|c|}
\hline \multirow[t]{2}{*}{ SI. No. } & \multicolumn{6}{|c|}{ Chemical Composition (Wt. \%) } \\
\hline & 0 & $\mathbf{P}$ & $\mathbf{S}$ & $\mathrm{Ti}$ & $M n$ & $\mathrm{Fe}$ \\
\hline 1 & 4.22 & 0.32 & 20.79 & 0.38 & 38.83 & 35.46 \\
\hline 2 & 3.82 & 0.44 & 15.75 & 0.36 & 26.98 & 52.65 \\
\hline
\end{tabular}

Table 2: EDS analysis of sample\#1.

\begin{tabular}{|c|c|c|c|c|}
\hline Sample No. & \multicolumn{3}{|c|}{ Inclusion Rating (ASTM E-45) } \\
\cline { 2 - 4 } & $\mathbf{A}(\mathbf{T} / \mathrm{H})$ & $\mathbf{B}(\mathbf{T} / \mathbf{H})$ & $\mathbf{C}(\mathbf{T} / \mathrm{H})$ \\
\hline 1 & $1.5 / 0.0$ & $0.0 / 0.0$ & $0.5 / 0.0$ \\
\hline
\end{tabular}

Table 3: Inclusion rating of sample\#1. 
originator of hook crack is non-metallic inclusion primarily $\mathrm{MnS}$ stringers. These flattened non-metallic inclusions are formed during hot rolling of plate. They reduce the ductile toughness of the steel even in their normal position but do not affect the mechanical strength of the steel [3]. Thus the tensile properties of the tube under investigation were also satisfactory. Close bond line these non-metallic incorporations reorient themselves such that they move toward becoming subjected to tractable loop pressure when the pipe is pressurized [4] and bringing about start of break. The slight bombshell of the metal at the weld acted to turn the finishes of this generally little subsurface break toward the surprise. Since the metal stream amid the surprise is toward the two surfaces. The hook of the hook crack may turn toward either the outside or inside surface, depending on which the delamination takes place in that direction where, the greatest amount of upset occurs. Generally the upset is greater toward the outer surface this causes the hook to turn towards outer surface [5]. In current examination additionally the break moved in the direction of the external surface because of more prominent miracle toward the external surface. Since snare splits are seen in the plate thickness thusly surface oxidation amid hot rolling and warmth treatment can't be in charge of snare break [6]. The chemical composition revealed higher high manganese and sulfur ratio and in this case favored the formation of $\mathrm{MnS}$ inclusion resulted in higher inclusion rating. These MnS inclusions caused deficiency at the edge of the strip which deviated towards the outside diameter of tube surface causing in hook crack creation during upsetting at the time of welding process. Thus the hook crack was originated during tube manufacturing which surfaced out when the tube was put in field service.

In case of Sample \#2, repeating chevron marks were observed to form a single line at certain interval on the tube surface. Similar marks with less severity and a line mark running through centre of these defects were observed at 180 degree location. Closer observation of the chevron marks in stereo microscope shows accumulation of material at centre of the chevron. Optical microscopy shows grain deformation at the defect contour indicating cold stage deformation. Based on the repetitive nature of the defect, it appears to be originating from the drawing stage itself and that too at exactly diametrically opposite locations of the tube. Decarburised grains along with internal oxidation associated with dark brown entrapment were observed along the cracks. Presence of mould power entrapment inside the crack indicates the defect originated from slab stage. The morphology and location on the tube suggests that the steel defect got aggravated during drawing forming the chevron mark. Mold powder entrapment occurs mainly in "transient casting" periods, e.g. the time of casting start, casting end, mold width change, ladle exchange, SEN change, etc. During the unsteady casting periods, usually, the casting speed is largely varied, which disturbs the flow of the liquid steel in the mold and results in severe fluctuation. Subsequently, shape powders are anything but difficult to be conveyed into the fluid steel and some are captured by the cemented shell and exist as non-metallic incorporations in sections. If the interfacial velocity of steel melt exceeds tear off velocity results in associated shear stress to become greater than the cohesion forces of the slag. Due to which slag gets torn off and carried over in the form of droplets in the liquid metal. While a part of these droplets immediately floats back towards the meniscus, another part is transported by the metal flow and scattered in the liquid pool [7]. In case of sample \#2 it has been observed that higher severity index in this coil is explained due to unstable stopper position shown in the caster (Figure 8). As seen

\begin{tabular}{|c|c|c|c|c|c|c|c|}
\hline \multirow[t]{2}{*}{ SI. No. } & \multicolumn{7}{|c|}{ Chemical Composition (Wt. \%) } \\
\hline & 0 & $\mathbf{F}$ & $\mathrm{Na}$ & Al & Si & $\mathrm{Ca}$ & $\mathrm{Fe}$ \\
\hline 1 & 22.44 & 4.94 & 4.66 & 2.92 & 10.41 & 16.52 & 38.11 \\
\hline 2 & 10.28 & 4.52 & 3.9 & 2.09 & 7.11 & 11.66 & 60.43 \\
\hline 3 & 17.5 & 1.88 & 8.8 & 7.0 & 10.4 & 5.78 & 48.65 \\
\hline
\end{tabular}

Table 4: EDS analysis of sample\#2.

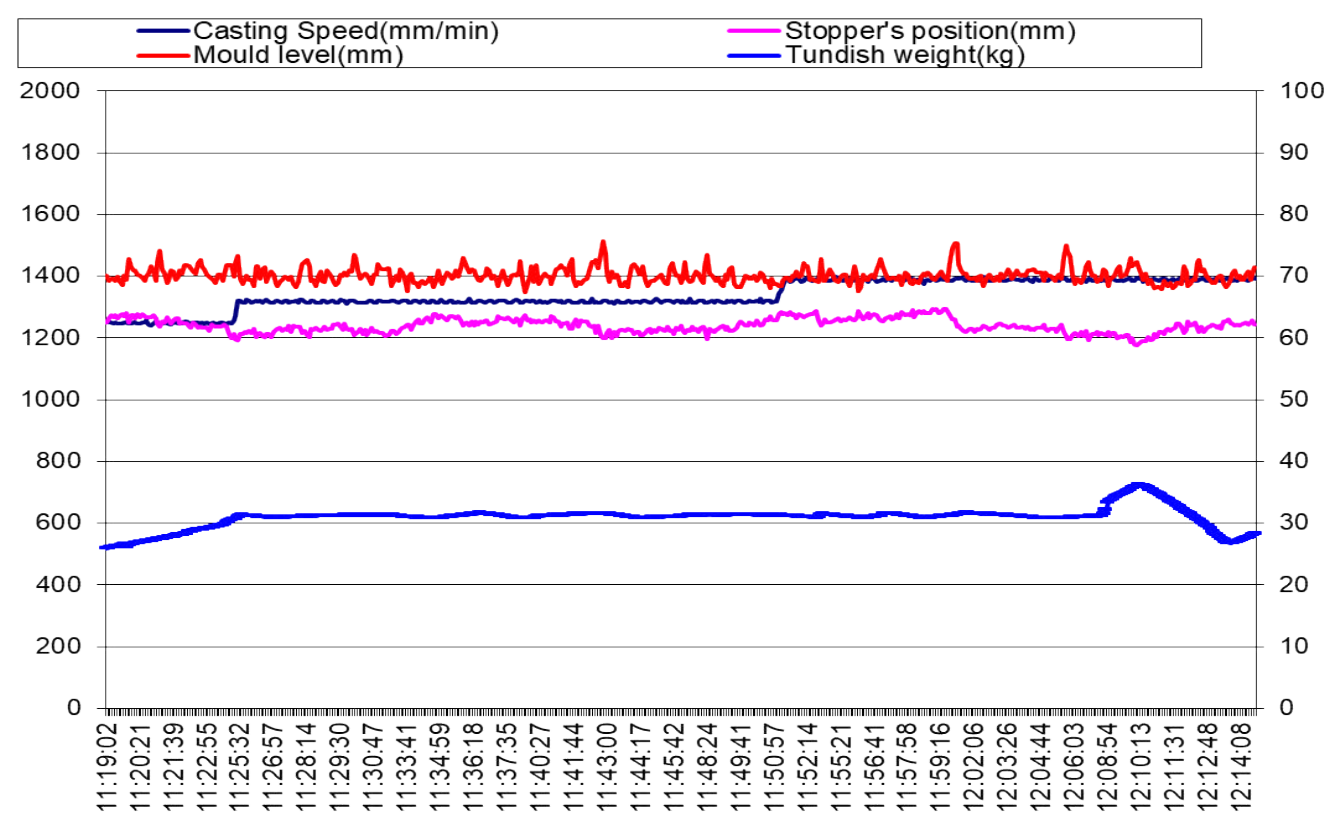

Figure 8: Casting parameters for the sample \#2. 
Citation: Das S, Lal J, Dey A, Mukhopadhyay G, Bhattacharya S (2018) Surface Defect in Telescopic Front Fork: A Metallurgical Analysis. J Steel Struct Constr 4: 143. doi: 10.4172/2472-0437.1000143

from the chart given for this slab, there are large fluctuations in casting speed along with large mold level fluctuations. Whereas casting speed in steady. Hence changing stopper position causes unstable molten steel flow and so entrapment of mold powder (Figure 8).

\section{Conclusion}

In Sample \#1: Analysis of the results suggests that the presence of $\mathrm{MnS}$ inclusion at the edge of the caused the origin of the hook crack, this exposed during process, resulting in cracking of tubes.

In Sample \#2: The slag entrapments of the mold fluxes in sub-surface of the strands are the main origin of the surface defect in telescopic fork tube. The morphology and location on the tube suggests that the steel defect got aggravated during drawing forming the chevron mark.

\section{Recommendation}

Failure of the fork tube can lead to the serious consequences. Careful inspection by sound magnetic flux leakage methods is required to assure that the defects are not present. Extra care should be taken to maintain the stopper position and casting speed regarding casting of surface critical grades to avoid non-metallic inclusions in the steel.

\section{References}

1. Quickel GT, Rollins BC, Beavers JA (2008) Analysis of seam weld related pipeline failures. Mater Sci Technol 8: 514-523.

2. Bhadeshia HKDH, Honeycombe RWK, (2011) Steel Microstructure and Properties pp. 299-301. Butterworth-Heinemann Publications, Boston.

3. Koo JY (1987) Welding metallurgy of structural steels. J Met 39: 31-35.

4. Rick MEADE, Tubesscope Pipeline Services, Houston, Texas (2006) Report submitted on non-destructive evaluation of low-frequency electric resistance welded pipe utilizing ultrasonic in-line inspection technology.

5. Becker WT, Shipley WT, Lampman SR, Sanders BR, Anton GJ, et al. (2002) ASM handbook. J Failure Anal Prev 11: 1072.

6. Dey A, Dhara S, Bhttacharyya T, Bhattacharyya S (2013) Cracking of Telescopic Front Fork Tube During Field Operation. J Failure Anal Prev 13: 292-297.

7. Das S, Roy S, Nayak S, Bhattacharyya T, Bhattacharyya S (2014) Case study: Analysis of grayish stick type sliver in cold rolled Strips. Engineering Failure Anal 44: 95-99. 